\title{
Preparation of porous tin dioxide powder by ultrasonic spray pyrolysis and their application to
} sensor materials

\author{
Koji Hieda, Takeo Hyodo, Yasuhiro Shimizu and Makoto Egashira* \\ Department of Materials Science and Engineering, Faculty of Engineering, Nagasaki University \\ 1-14 Bunkyo-machi, Nagasaki 852-8521, Japan \\ *egashira@nagasaki-u.ac.jp
}

\begin{abstract}
Porous $\mathrm{SnO}_{2}$ powders have been prepared by pyrolysis of atomized aqueous $\mathrm{SnCl}_{2}$ or $\mathrm{SnCl}_{4}$ precursor solutions containing polymethylmethacrylate (PMMA) microspheres. The diameter of macropores existing in the porous $\mathrm{SnO}_{2}$ powders (about 400 800 nm in diameter) was about 150 200 nm. In addition, the wall thickness of the porous $\mathrm{SnO}_{2}$ powder prepared from $\mathrm{SnCl}_{2}$ was presumed to be thinner than that prepared from $\mathrm{SnCl}_{4}$. A SnO 2 sensor fabricated from the powder prepared by pyrolysis of the aqueous $\mathrm{SnCl}_{2}$ solution at $1100^{\circ} \mathrm{C}$ showed the highest response to $1000 \mathrm{ppm}_{2}$ in air among the sensors tested.
\end{abstract}

\section{Introduction}

$\mathrm{SnO}_{2}$ is well-known as the most important material for semiconductor gas sensors because of its relatively high gas sensing properties as well as high chemical stability $[1,2]$. For further improvement of the gas sensitivity and selectivity, however, strict control of gas reactivity and selectivity is indispensable. Therefore, we have so far demonstrated the optimization of nanoand micro-structure of the sensors by utilizing various techniques. For example, the introduction of ordered mesoporous structure into $\mathrm{SnO}_{2}$ powder was found to be very effective for controlling the gas diffusivity and reactivity [3-6]. Chemical surface modification of $\mathrm{SnO}_{2}$ powder with some kinds of alkoxysilanes was also found to be very promising as a technique for getting high performance sensors, because the gas diffusivity and potential barrier height among $\mathrm{SnO}_{2}$ grains could be controlled precisely [7-10]. In addition, it was revealed that anodically oxidized titania films coupled with a palladium electrode were potential diode-type $\mathrm{H}_{2}$ sensor materials with a Schottky barrier at the palladium-oxide interface [11-14]. 
By the way, an ultrasonic spray pyrolysis method is one of the effective techniques for preparing highly dispersed oxide powders. Recently, we have succeeded to prepare submicron-size hollow alumina microspheres with controlled thickness and crystal structure [15, 16]. It is worth noting that Iskandar et al. have prepared various kinds of oxide microspheres involving macropores by thermal decomposition of atomized oxide precursor solutions containing submicron-sized polystyrene microspheres as a template $[17,18]$. The introduction of macropores into the constituent materials for some electrochemical devices such as fuel cells and chemical sensors is very important to improve their performance, because reactants and products of the electrochemical reactions should be diffused or transferred easily through the macropores. Actually, we have demonstrated that well-developed macroporous ceramic films, which were prepared by a modified sol-gel technique by employing polymetheylmethacrylate (PMMA) microspheres as a template, showed excellent sensing properties to $\mathrm{H}_{2}$ and $\mathrm{NO}_{x}$ [19-21].

In this study, therefore, attempts have been made to prepare porous $\mathrm{SnO}_{2}$ powders by pyrolysis of atomized aqueous precursor solutions containing PMMA microspheres. Then, potential of these porous $\mathrm{SnO}_{2}$ powders as a new sensor material has been examined.

\section{Experimental}

\subsection{Preparation of porous $\mathrm{SnO}_{2}$ powder by ultrasonic spray pyrolysis method}

PMMA microspheres (Soken Chem. \& Eng. Co., Ltd., $250 \mathrm{~nm}$ in diameter) of $0.5 \mathrm{~g}$ were added to $0.05 \mathrm{~mol} \mathrm{dm}^{-3} \mathrm{SnCl}_{2}$ or $\mathrm{SnCl}_{4}$ aqueous solutions of $100 \mathrm{ml}$, and the mixtures were served as precursor solutions for preparation of porous $\mathrm{SnO}_{2}$ powders by ultrasonic spray pyrolysis. In some cases, $\mathrm{SbCl}_{3}$ was also added to the mixtures at a level of 0.1 wt $\%$ of the weight of $\mathrm{SnCl}_{2}$ or $\mathrm{SnCl}_{4}$ in order to improve the conductivity of resultant $\mathrm{SnO}_{2}$ powder. We used a flow spray pyrolysis system equipped with a specially designed mist-supply to prepare porous $\mathrm{SnO}_{2}$ powder in an electric furnace, as shown in Fig. 1. The mist of the precursor solutions was generated in a plastic container equipped with a polyethylene thin film at one end, which was set perpendicular over an ultrasonic vibrator (Honda Electric Co., Ltd., HM-303N, $2.4 \mathrm{MHz}$ ) at a distance of $0.5 \sim 1.0 \mathrm{~cm}$ in water. And then, the mist was carried into a glass vessel by air flowing $1\left(1.5 \mathrm{dm}^{3} \mathrm{~min}^{-1}\right)$, and only small droplets were allowed to move into an electric furnace heated at $800 \sim 1100^{\circ} \mathrm{C}$ with a help of air flowing $2\left(1.5 \mathrm{dm}^{3} \mathrm{~min}^{-1}\right)$. Porous $\mathrm{SnO}_{2}$ powders obtained were characterized by transmission electron microscopy (TEM), scanning electron microscopy (SEM) and X-ray diffraction analysis (XRD). Porous $\mathrm{SnO}_{2}\left(\mathrm{pr}-\mathrm{SnO}_{2}\right.$, pr means "porous") powders prepared by $\mathrm{SnCl}_{2}$ and $\mathrm{SnCl}_{4}$ solutions are denoted as $\mathrm{pr}^{-} \mathrm{SnO}_{2}(\mathrm{n}) \mathrm{T}$ in this 
study ( $\mathrm{n}$ : raw material, $\mathrm{d}$ for $\mathrm{SnCl}_{2}$ and $\mathrm{t}$ for $\mathrm{SnCl}_{4}$, respectively, and $\mathrm{T}$ : the calcination temperature $\left(800 \sim 1100^{\circ} \mathrm{C}\right)$ ). In addition, Sb-doped $\mathrm{SnO}_{2}$ is referred to as $\mathrm{pr}-\mathrm{Sb} / \mathrm{SnO}_{2}(\mathrm{n}) \mathrm{T}$. For comparative purpose, a conventional $\mathrm{SnO}_{2}\left(\mathrm{c}-\mathrm{SnO}_{2}\right)$ powder was prepared by pyrolysis of tin oxalate at $600^{\circ} \mathrm{C}$ for $5 \mathrm{~h}$.

\subsection{Fabrication of sensors and their hydrogen sensing properties}

Thick film sensors were fabricated by applying the paste of pr-SnO ${ }_{2}(n) T$, pr-Sb/SnO ${ }_{2}(n) T$ or $\mathrm{c}-\mathrm{SnO}_{2}$ powder on alumina substrates equipped with a pair of interdigitated Pt electrodes, followed by calcination at $550^{\circ} \mathrm{C}$ for $5 \mathrm{~h}$. Gas responses of these sensors were measured to $1000 \mathrm{ppm} \mathrm{H}_{2}$ balanced with air in a flow apparatus at $250 \sim 500^{\circ} \mathrm{C}$. Sensor response was defined as the ratio $\left(R_{a} / R_{\mathrm{g}}\right)$ of sensor resistance in air $\left(R_{\mathrm{a}}\right)$ to that in $\mathrm{H}_{2}$ balanced with air $\left(R_{\mathrm{g}}\right)$.

\section{Results and discussion}

\subsection{Characterization of $\mathrm{pr}-\mathrm{SnO}_{2}(n) \mathrm{T}$ and $\mathrm{pr}-\mathrm{Sb} / \mathrm{SnO}_{2}(n) 1100$ powders}

XRD patterns of four kinds of pr-SnO $2(\mathrm{~d}) \mathrm{T}$ and $\mathrm{pr}-\mathrm{SnO}_{2}(\mathrm{t}) 1100$ powders are shown in Fig. 2. All specimens exhibited casserite-type structure, while the crystallite size (CS) of the pr-SnO $\mathrm{S}_{2}(\mathrm{~d}) \mathrm{T}$ powder calculated by the Scherrer equation increased with a rise in pyrolysis temperature. In addition, the kind of Sn-source seems to have a large influence on the value of

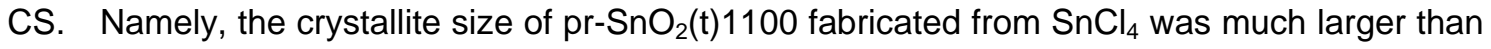
that of $\mathrm{pr}_{-} \mathrm{SnO}_{2}(\mathrm{~d}) 1100$ fabricated from $\mathrm{SnCl}_{2}$.

TEM images of pr-SnO ${ }_{2}(d) T(T=800 ~ 1100)$ and pr-SnO ${ }_{2}(t) 1100$ are shown in Fig. 3. Many macropores replicating the shape of submicron-size PMMA microspheres (d: $250 \mathrm{~nm})$ were observed in all the resultant porous $\mathrm{SnO}_{2}$ particles. The diameter of macropores existing in the porous $\mathrm{SnO}_{2}$ powder (about 400 800 nm in diameter), about 150 200 nm, was slightly reduced from that of PMMA microspheres. Formation of such spherical macropores may suggest the slower pyrolysis rate of PMMA than that of tin chloride. In addition, we can see that the morphology of macropores is not dependent on the pyrolysis temperature, suggesting high thermal stability of the porous structure. Furthermore, it was revealed in high magnification TEM images that one granular particle consisted of many very fine particles. The mean particle sizes (PS) observed are indicated in Fig. 3. These values are well coincident with the crystallite sizes calculated by the Scherrer equation (see Fig. 2). Another notable finding is that the image

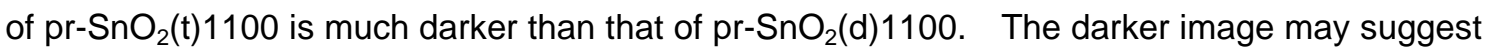
thicker $\mathrm{SnO}_{2}$ walls inside the granular particle. Furthermore, the particle size of $\mathrm{pr}_{-} \mathrm{SnO}_{2}(\mathrm{~d}) 1100$ 


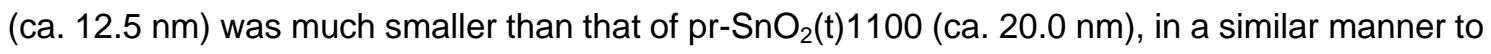
the order of crystallite size.

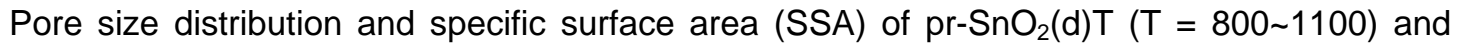
pr-SnO ${ }_{2}(\mathrm{t}) 1100$ are shown in Fig. 4. These specimens showed relatively smaller SSA than that of mesoporous $\mathrm{SnO}_{2}$ powder prepared from $\mathrm{Na}_{2} \mathrm{SnO}_{3}$ as a tin source and cetyltrimethylchloride as a mesopore template (ca. $300 \mathrm{~m}^{2} \mathrm{~g}^{-1}$ after calcination at $600^{\circ} \mathrm{C}$ for $5 \mathrm{~h}$ ) [3, 4], because of the high pyrolysis temperature $\left(800 \sim 1100^{\circ} \mathrm{C}\right)$. However, SSA of pr-SnO ${ }_{2}(\mathrm{~d}) \mathrm{T}(\mathrm{T}=800 \sim 1100)$ was much larger than that of $\mathrm{c}-\mathrm{SnO}_{2}$ powder prepared by pyrolysis of tin oxalate at $600^{\circ} \mathrm{C}$ for $5 \mathrm{~h}$ as a reference, whereas that of $\mathrm{pr}^{-} \mathrm{SnO}_{2}(\mathrm{t}) 1100$ showed a much smaller SSA value. Specific surface area of three kinds of pr-SnO ${ }_{2}(\mathrm{~d}) \mathrm{T}$ powders pyrolyzed at temperatures less than $1000^{\circ} \mathrm{C}$ was almost comparable to each other, but pr-SnO ${ }_{2}(d) 1100$ showed the smallest surface area among the powders prepared from $\mathrm{SnCl}_{2}$. This result may be explained by a decrease in the amount of pores with sizes of 2 $4 \mathrm{~nm}$ in diameter. In addition, from the comparison between the pore size distribution and TEM images (Figs. 3(a)' (d)'), we can understand that nanopores of less than about $4 \mathrm{~nm}$ reflect the spaces formed among crystallites, while mesopores of about $30 \mathrm{~nm}$ seem to correspond to the spaces formed among crystallite agglomerates. However, the larger SSA of pr-SnO $(\mathrm{d}) 1100$ than $\mathrm{pr}-\mathrm{SnO}_{2}(\mathrm{t}) 1100$ may reflect large amounts of nano (ca. $4 \mathrm{~nm}$ in diameter) and mesopores (ca. $30 \mathrm{~nm}$ in diameter), as shown in Fig. 4(d).

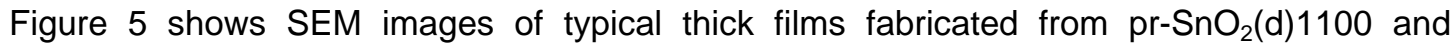

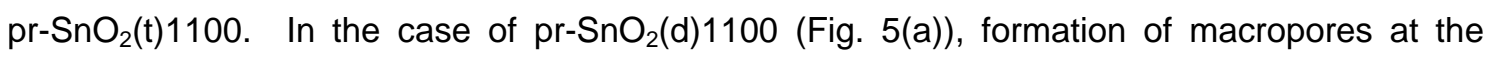
surface of $\mathrm{SnO}_{2}$ powder was obscure due to formation of many $\mathrm{SnO}_{2}$ nanoparticles, which have already been observed around pr-SnO $\mathrm{S}_{2}(\mathrm{~d}) 1100$ powder in Fig. 3(d). The morphology of other

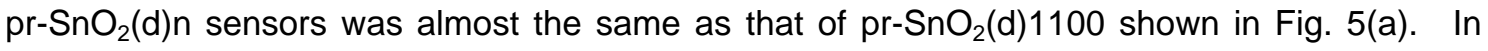

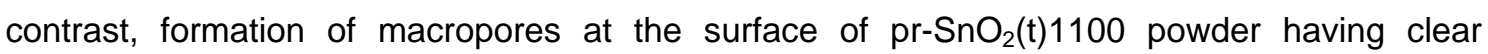
boundaries among them is obvious in Fig. 5(b), then little nanoparticles appear.

3.2. $\mathrm{H}_{2}$ sensing properties of thick film pr-SnO $\mathrm{S}_{2}(n) T$ sensors and the effects of Sb-doping to pr-SnO ${ }_{2}(n) 1100$

Typical response transients to $1000 \mathrm{ppm} \mathrm{H}_{2}$ of $\mathrm{pr}^{-\mathrm{SnO}_{2}(\mathrm{~d}) 1100 \text { and c-SnO }}{ }_{2}$ sensors are shown in Fig. 6. The pr-SnO ${ }_{2}(d) 1100$ sensor showed relatively slow response and recovery speeds and extremely high resistance in air, compared with those of $\mathrm{c}-\mathrm{SnO}_{2}$. However, the magnitude of response $\left(R_{a} / R_{g}\right)$ of pr-SnO $(\mathrm{d}) 1100$ was much higher than that of $\mathrm{c}-\mathrm{SnO}_{2}$. Figure 7 shows

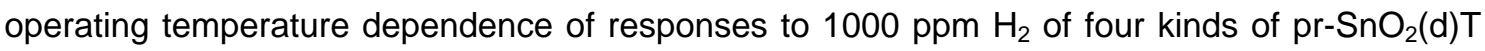
and $\mathrm{c}-\mathrm{SnO}_{2}$ sensors. The maximum $R_{\mathrm{a}} / R_{\mathrm{g}}$ of the $\mathrm{c}-\mathrm{SnO}_{2}$ sensor was ca. 20 at $400^{\circ} \mathrm{C}$. On the other hand, $\mathrm{pr}-\mathrm{SnO}_{2}(\mathrm{~d}) \mathrm{T}$ sensors, fabricated from porous $\mathrm{SnO}_{2}$ powders involving macropores, 
showed larger $\mathrm{H}_{2}$ response than the $\mathrm{c}-\mathrm{SnO}_{2}$ sensor, probably because porous $\mathrm{SnO}_{2}$ powders had a large surface area, and then a large number of active sites. $\mathrm{H}_{2}$ gas diffusion control may have been generated by such macroporous structure, and then have contributed to the enlargement of $\mathrm{H}_{2}$ gas response. The $R_{\mathrm{a}} / R_{\mathrm{g}}$ of pr-SnO${ }_{2}(\mathrm{~d}) 1100$ (ca. 60 at $350^{\circ} \mathrm{C}$ ) showed the highest value among pr-SnO ${ }_{2}(\mathrm{~d}) \mathrm{T}$ sensors, while it showed extremely high resistance in air (see Fig. 6(a)). As shown in Figs. 2 and 4, the $\mathrm{pr}^{-} \mathrm{SnO}_{2}(\mathrm{~d}) 1100$ sensor showed the largest crystallite

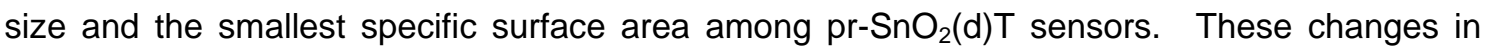
microstrucutre induced by a rise in calcination temperature usually leads to a decrease in gas response. However, the fact that the largest response observed with the pr-SnO ${ }_{2}(d) 1100$ sensor implies the existence of other response determining factors, such as optimization of gas diffusivity and reactivity at the surface of sensor materials. Also in the case of the pr-SnO $(\mathrm{t}) 1100$ sensor fabricated from the $\mathrm{SnCl}_{4}$ precursor solution, the $\mathrm{H}_{2}$ response could not be measured due to its extremely high sensor resistance. Therefore, Sb-doping into the Sn sites of $\mathrm{pr}-\mathrm{SnO}_{2}(\mathrm{n}) 1100$ was attempted to decrease the sensor resistance in air.

Response transients of $\mathrm{pr}-\mathrm{Sb} / \mathrm{SnO}_{2}(\mathrm{~d}) 1100$ and $\mathrm{pr}-\mathrm{Sb} / \mathrm{SnO}_{2}(\mathrm{t}) 1100$ sensors are shown in Fig. 8. The sensor resistance of $\mathrm{pr}-\mathrm{Sb} / \mathrm{SnO}_{2}$ (d) 1100 could be reduced by two orders of magnitude by the Sb-doping. In addition, the response and recovery speeds could also be improved drastically, and they were faster than those of the $\mathrm{c}-\mathrm{SnO}_{2}$ sensor. In contrast, the resistance of the $\mathrm{pr}-\mathrm{Sb} / \mathrm{SnO}_{2}(\mathrm{t}) 1100$ sensor in air could be decreased to a level capable of measuring, but it was still too high to be put into practical use, along with terribly slow response and recovery speeds.

However, the Sb-doping reduced the response to $\mathrm{H}_{2}$. Operating temperature dependences of responses to $1000 \mathrm{ppm} \mathrm{H}$ of the pr-Sb/SnO ${ }_{2}(\mathrm{~d}) 1100$ and $\mathrm{pr}-\mathrm{Sb} / \mathrm{SnO}_{2}(\mathrm{t}) 1100$ sensors are shown in Fig. 9. For reference, the result of the $\mathrm{c}-\mathrm{SnO}_{2}$ sensor is cited again in Fig. 9. All the sensors showed good reproducibility in sensing properties within our laboratory test period. The response of the $\mathrm{pr}-\mathrm{Sb} / \mathrm{SnO}_{2}(\mathrm{~d}) 1100$ sensor was much smaller than that of the pr-SnO $(\mathrm{d}) 1100$ sensor and was comparable to that of the $\mathrm{c}-\mathrm{SnO}_{2}$ sensor. On the other hand, the $\mathrm{pr}-\mathrm{Sb} / \mathrm{SnO}_{2}(\mathrm{t}) 1100$ sensor showed larger $\mathrm{H}_{2}$ response than the $\mathrm{c}-\mathrm{SnO}_{2}$ sensor, but the extremely high resistance and terribly slow response and recovery speeds (Fig. 8(b)) are the problem. Further improvement of the sensor properties are now under investigation by various techniques such as strict control of the sensor nanostructure, surface modification and noble-metal doping.

\section{Conclusion}


Porous $\mathrm{SnO}_{2}$ powders (the diameter: 400 800 nm, spherical pore diameter: 150 200 nm) have been prepared by pyrolysis of atomized aqueous $\mathrm{SnCl}_{2}$ or $\mathrm{SnCl}_{4}$ precursor solutions containing PMMA microspheres. The morphology of macropores replicating the shape of submicron-size PMMA microspheres was found to be less dependent on the pyrolysis temperature, suggesting high thermal stability of the porous structure. Specific surface area of

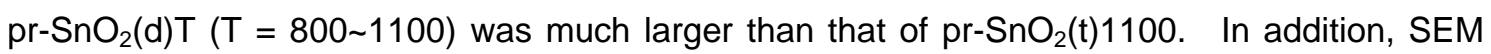
images of pr-SnO ${ }_{2}(\mathrm{~d}) 1100$ showed that macropores were obscure at the surface of $\mathrm{SnO}_{2}$ powder due to formation of many $\mathrm{SnO}_{2}$ nanoparticles. In contrast, formation of macropores at the surface of $\mathrm{p}-\mathrm{SnO}_{2}(\mathrm{t}) 1100$ powder having clear boundaries among them was observed clearly, probably due to less formation of nanoparticles.

The $R_{\mathrm{a}} / R_{\mathrm{g}}$ of pr-SnO ${ }_{2}$ (d)1100 (ca. 60 at $350^{\circ} \mathrm{C}$ ) showed the highest value among pr-SnO ${ }_{2}(\mathrm{~d}) \top$ sensors, while it showed extremely high resistance in air. Sb-doping into the Sn sites of

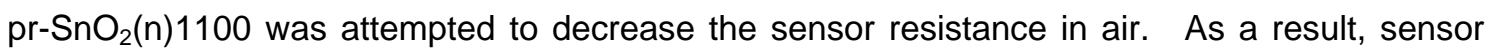
resistance and $\mathrm{H}_{2}$ response decreased, but response and recovery speeds of the pr-SnO $($ d $) 1100$ sensor drastically improved.

\section{References}

1. N. Yamazoe, New approaches for improving semiconductor gas sensors, Sens. Actuators B 5 (1991) 7-19.

2. Y. Shimizu, M. Egashira, Basic aspects and challenges of semiconductor gas sensors, MRS Bull. 24 (1999) 18-24.

3. T. Hyodo, N. Nishida, Y. Shimizu, M. Egashira, Preparation and gas-sensing properties of thermally stable meesoporous $\mathrm{SnO}_{2}$, Sens. Actuators B 83 (2002) 209-215.

4. T. Hyodo, S. Abe, Y. Shimizu, M. Egashira, Gas sensing properties of ordered mesoporous $\mathrm{SnO}_{2}$ and effects of coatings thereof, Sens. Actuators B 93 (2003) 590-600.

5. T. Hyodo, Y. Mitsuyasu, Y. Shimizu, M. Egashira, $\mathrm{H}_{2}$ and NOx sensing properties of $\mathrm{ZnO}$ and $\mathrm{In}_{2} \mathrm{O}_{3}$ powders modified with mesoporous $\mathrm{SnO}_{2}$, J. Ceram. Soc. Jpn. 112 (2004) S540-545.

6. Y. Shimizu, K. Tsumura, T. Hyodo, M. Egashira, Effect of simultaneous modification with metal loading and mesoporous layer on $\mathrm{H}_{2}$ sensing properties of $\mathrm{SnO}_{2}$ thick film sensors, IEEJ Trans. SM 125 (2005) 70-74.

7. Y. Shimizu, E. Di Bartolomeo, E. Traversa, G. Gusmano, T. Hyodo, K. Wada, M. Egashira, Effect of surface modification on $\mathrm{NO}_{2}$ sensing properties of $\mathrm{SnO}_{2}$ varistor-type sensors, Sens. Actuators B 60 (1999) 118-124. 
8. K. Wada, M. Egashira, Hydrogen sensing properties of $\mathrm{SnO}_{2}$ subjected to surface chemical modification with ethoxysilanes, Sens. Actuators B 62 (2000) 211-219.

9. T. Hyodo, Y. Baba, K. Wada, Y. Shimizu, M. Egashira, Hydrogen sensing properties of $\mathrm{SnO}_{2}$ varistors loaded with $\mathrm{SiO}_{2}$ by surface chemical modification with diethoxydimethylsilane, Sens. Actuators B 64 (2000) 175-181.

10. K. Wada, M. Egashira, Effects of Pd- and Pt-loading on the gas-sensing properties of $\mathrm{SnO}_{2}$ subjected to surface chemical modification with diethoxydimethylsilane, T. IEE Japan 120-E (2000) 458-467.

11. Y. Shimizu, N. Kuwano, T. Hyodo, M. Egashira, High $\mathrm{H}_{2}$ sensing performance of anodically oxidized $\mathrm{TiO}_{2}$ film contacted with Pd, Sens. Actuators B 83 (2002) 195-201.

12. T. Iwanaga, T. Hyodo, $\mathrm{Y}$. Shimizu, M. Egashira, $\mathrm{H}_{2}$ sensing properties and mechanism of anodically oxidized $\mathrm{TiO}_{2}$ film contacted with Pd electrode, Sens. Actuators B 93 (2003) 519-525.

13. T. Hyodo, T. Iwanaga, Y. Shimizu, M. Egashira, Effects of electrode materials and oxygen partial pressure on the hydrogen sensing properties of anodically oxidized titanium dioxide films, ITE Lett. 4 (2003) 594-597.

14. H. Miyazaki, T. Hyodo, Y. Shimizu, M. Egashira, Hydrogen sensing properties of anodically oxidized $\mathrm{TiO}_{2}$ film sensors -effects of preparation and pretreatment conditions-, Sens. Actuators B 108 (2005) 467-472.

15. T. Kato, M. Tashiro, K. Sugimura, T. Hyodo, Y. Shimizu, M. Egashira, Preparation of hollow alumina microspheres by ultrasonic spray pyrolysis, J. Ceram. Soc. Jpn 110 (2002) 146-148.

16. M. Egashira, T. Kato, T. Hyodo, Y. Shimizu, Preparation of hollow alumina microspheres by mechanofusion and ultrasonic spray pyrolysis, Key Eng. Mater. 247 (2003) 427-432.

17. F. Iskandar, Mikrajuddin, K. Okuyama, In situ production of spherical silica particles containing self-organized mesopores, Nano Lett. 1 (2001) 231-234.

18. F. Iskandar, Mikrajuddin, K. Okuyama, Controllability of pore size and porosity on self-organized porous silica particles, Nano Lett. 2 (2002) 389-392.

19. T. Hyodo, K. Sasahara, Y. Shimizu, M. Egashira, Preparation of macroporous $\mathrm{SnO}_{2}$ films using PMMA microspheres and their sensing properties to $\mathrm{NO}_{x}$ and $\mathrm{H}_{2}$, Sens. Actuators $B$ 106 (2005) 580-590.

20. T. Ishibashi, T. Hyodo, Y. Shimizu, M. Egashira, Preparation of macroporous $\mathrm{SnO}_{2}$ thick films and their application to sensor materials, Chemical Sensors VI, The Electrochem. Soc. 8 (2004) 28-35.

21. H. Seh, T. Hyodo, H. L. Tuller, Bulk acoustic wave resonator as a sensing platform for $\mathrm{NO}_{x}$ at high temperatures, Sens. Actuators B 108 (2005) 547-552. 


\section{Figure caption}

Fig. 1. A schematic drawing and a photograph of a feeding system of a precursor solution atomized by ultrasonication.

Fig. 2. XRD patterns of $\mathrm{pr}-\mathrm{SnO}_{2}(\mathrm{~d}) \mathrm{T}(\mathrm{T}=800 \sim 1100)$ and $\mathrm{pr}-\mathrm{SnO}_{2}(\mathrm{t}) 1100$.

Fig. 3. TEM images of various porous $\mathrm{SnO}_{2}$ particles, a e: low magnification and a' $\sim$ ': high magnification. a and a': pr-SnO $2(d) 800$, b and b': pr-SnO $(d) 900, c$ and c':

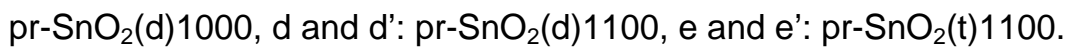

Fig. 4. Pore size distributions of $\mathrm{pr}-\mathrm{SnO}_{2}(\mathrm{~d}) \mathrm{T}(\mathrm{T}=800 \sim 1100)$, $\mathrm{pr}-\mathrm{SnO}_{2}(\mathrm{t}) 1100$ and c-SnO${ }_{2}$.

Fig. 5. SEM images of thick film pr-SnO $2(n) 1100(n: d$ and t) sensors.

Fig. 6. Response transients of thick film pr-SnO ${ }_{2}(\mathrm{~d}) 1100$ and c-SnO ${ }_{2}$ sensors to $1000 \mathrm{ppm} \mathrm{H}_{2}$ at $300^{\circ} \mathrm{C}$.

Fig. 7. Temperature dependence of response of thick film pr-SnO ${ }_{2}(d) T(T=800 \sim 1100)$ and c-SnO ${ }_{2}$ sensors to 1000 ppm $\mathrm{H}_{2}$ balanced with air.

Fig. 8. Response transients of thick film pr-Sb/SnO $2(n) 1100(n: d$ and t) sensors to $1000 \mathrm{ppm}$ $\mathrm{H}_{2}$ at $300^{\circ} \mathrm{C}$.

Fig. 9. Temperature dependence of response of thick film pr-Sb/SnO ${ }_{2}(n) 1100(n: d$ and t) and c-SnO ${ }_{2}$ sensors to 1000 ppm $\mathrm{H}_{2}$ balanced with air. 


\section{Biographies of authors}

Koji Hieda received his B. Eng. Degree in materials science and engineering in 2006 from Nagasaki University. He is now a student in Graduate School of Science and Technology, Nagasaki University, and is currently engaged in research and development of an adsorption/combustion-type sensor.

Takeo Hyodo received his B Eng Degree in applied chemistry and M Eng Degree in materials science and technology in 1992 and 1994, respectively, and Dr Eng Degree in 1997 from Kyushu University. He has been a research associate at Nagasaki University since 1997. His current interests are the development of electrochemical devices such as chemical sensors and lithium batteries, and mesoporous and macroporous materials.

Yasuhiro Shimizu received his B Eng Degree in applied chemistry in 1980 and Dr Eng Degree in 1987 from Kyushu University. He has been a professor at Nagasaki University since 2005. His current research concentrates on design of intelligent sensors by controlling gas diffusivity and reactivity, development of new sensor materials.

Makoto Egashira received his B Eng Degree and M Eng Degree in applied chemistry in 1966 and 1968, respectively, and Dr Eng Degree in 1974 from Kyushu University. He has been a professor at Nagasaki University since 1985. His current interests include the development of new chemical sensors and surface modification of ceramics, preparation of hollow ceramic microspheres and porous films. 


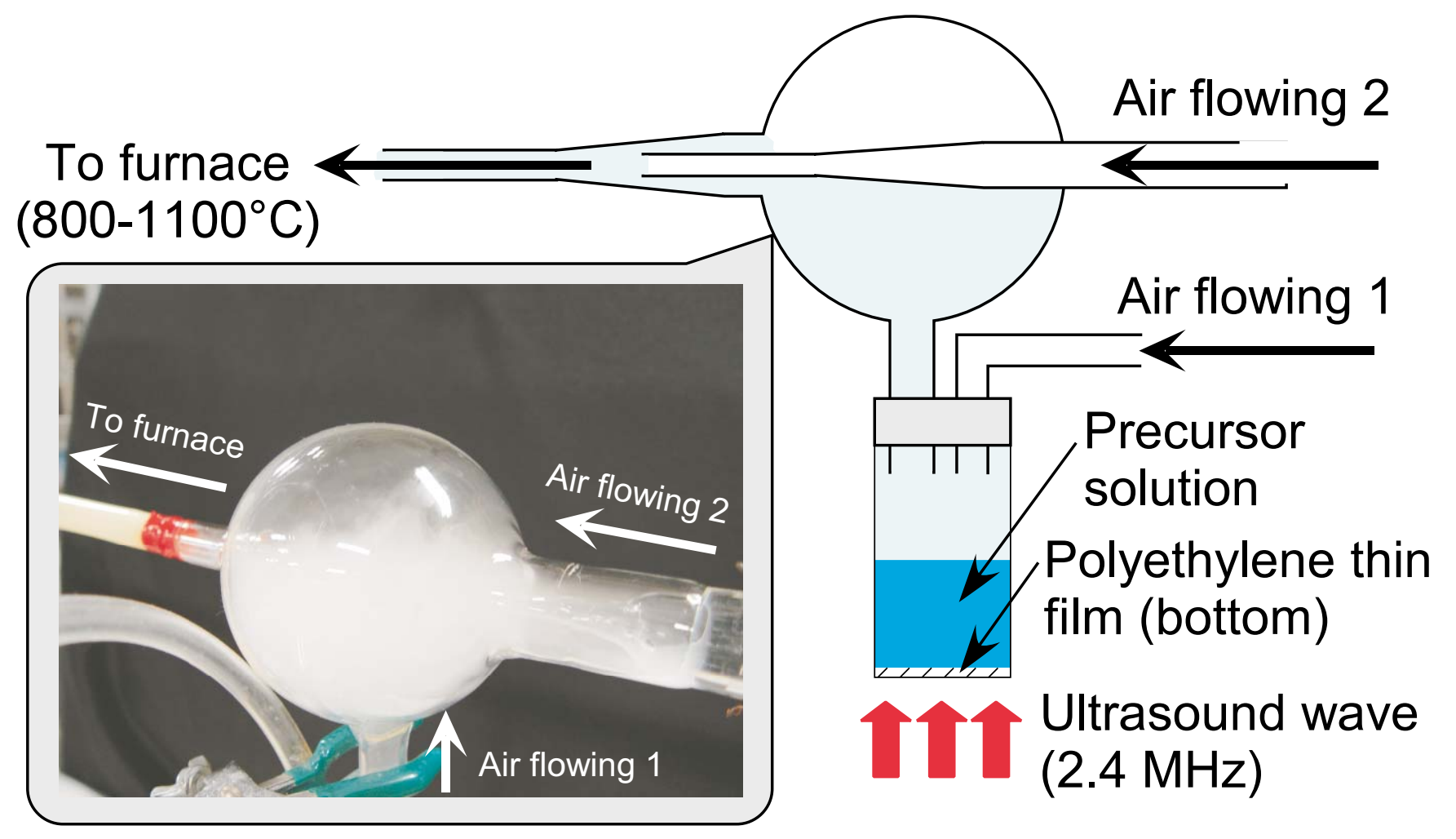

Fig. 1. Hieda et al. 


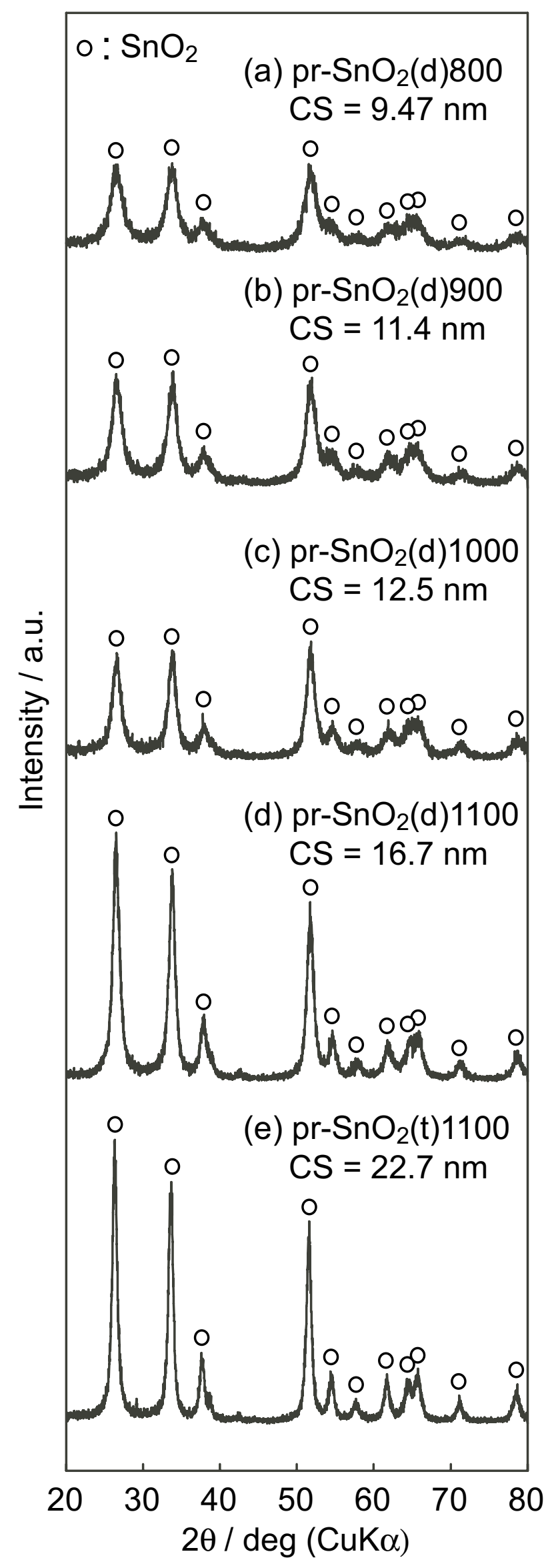

Fig. 2. Hieda et al. 
(a)

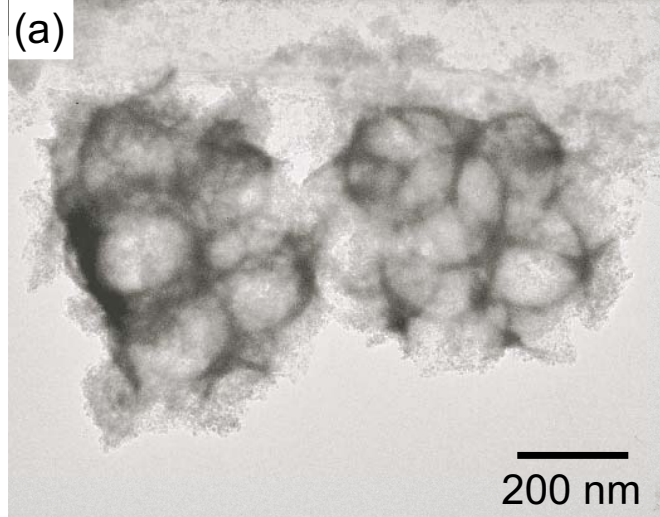

(a)'

$P S=7.50 \mathrm{~nm}$

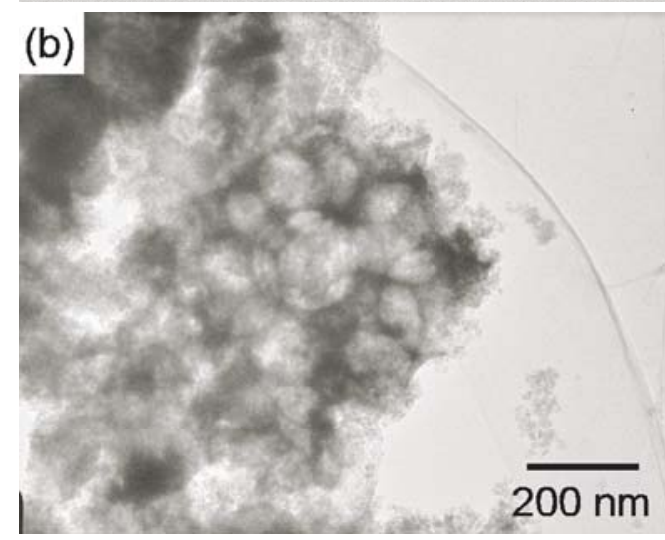

(b)'

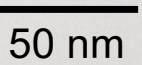

(c)

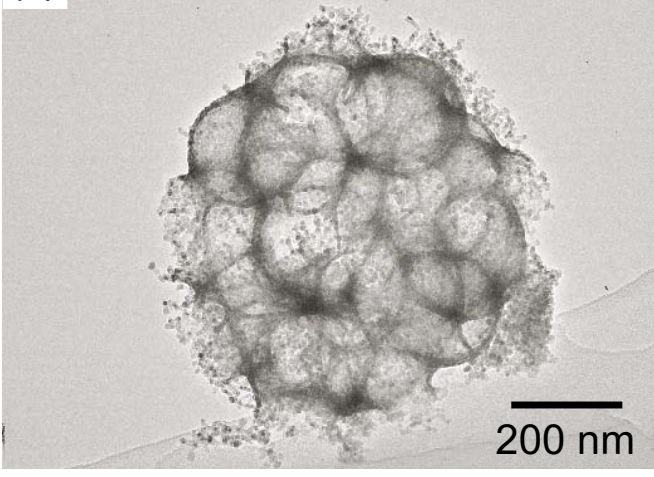

(c)'

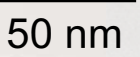

(d)

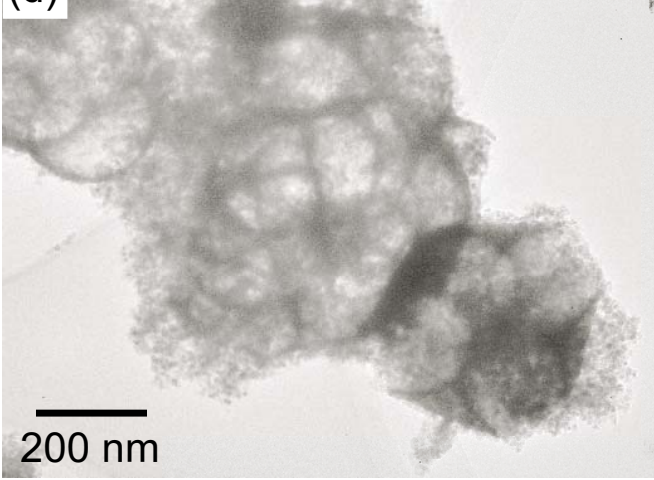

(d)'
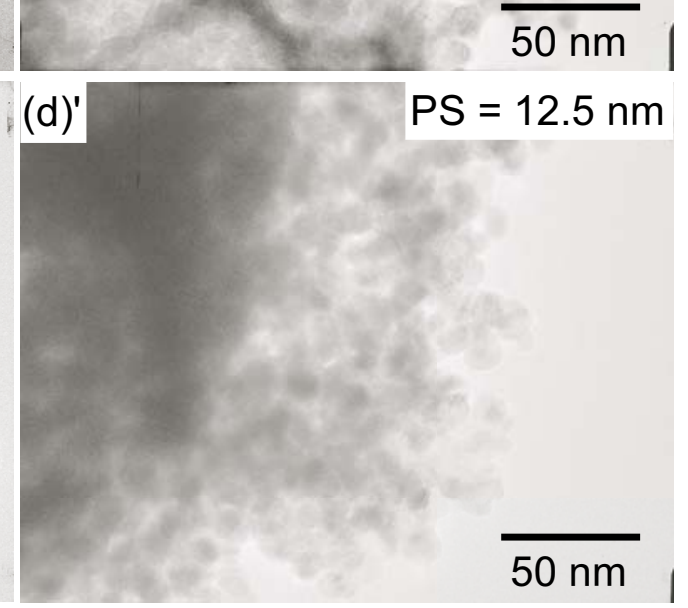

(e)

(e)'

$\mathrm{PS}=20.0 \mathrm{~nm}$

$\overline{200 \mathrm{~nm}}$

Fig. 3. Hieda et al. 


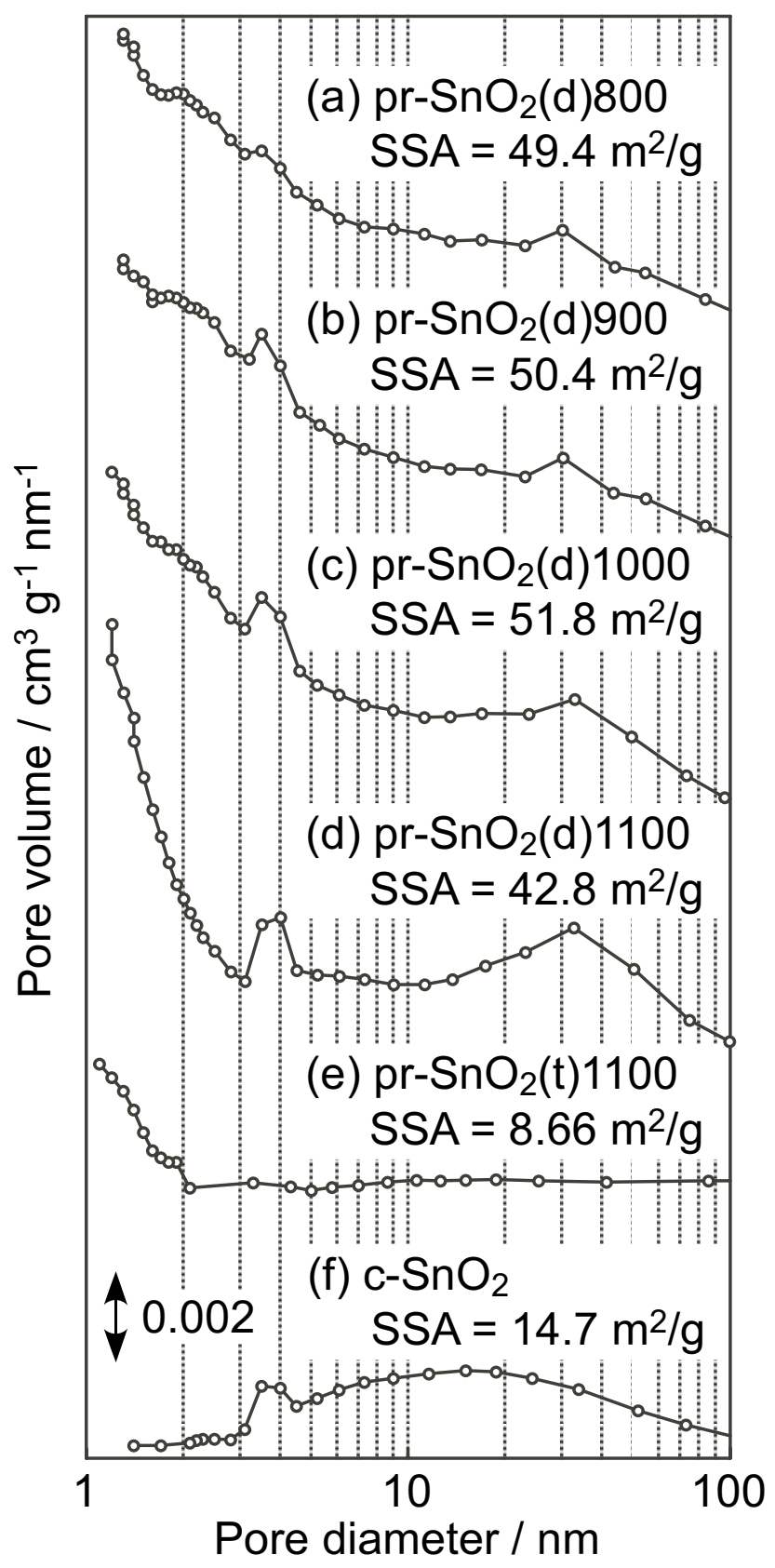

Fig. 4. Hieda et al. 

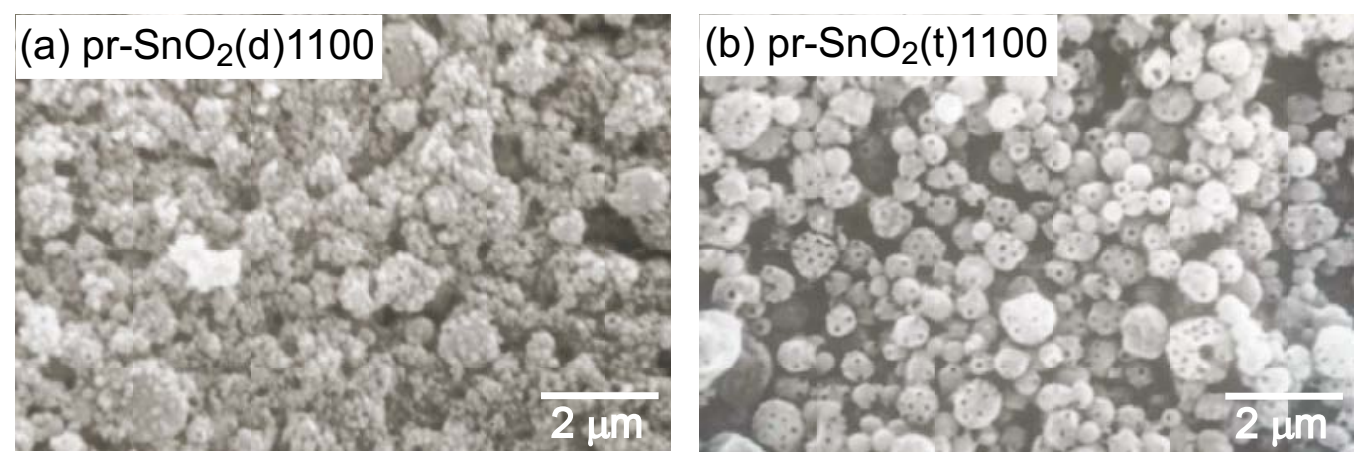

Fig. 5. Hieda et al. 


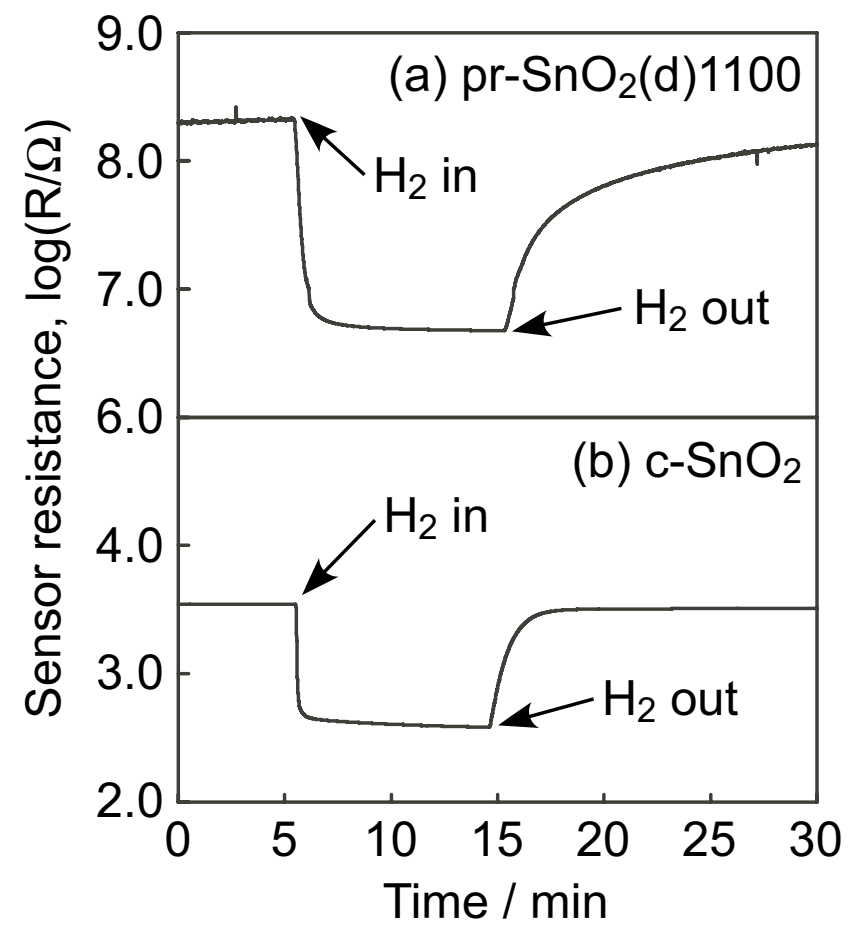

Fig. 6. Hieda et al.

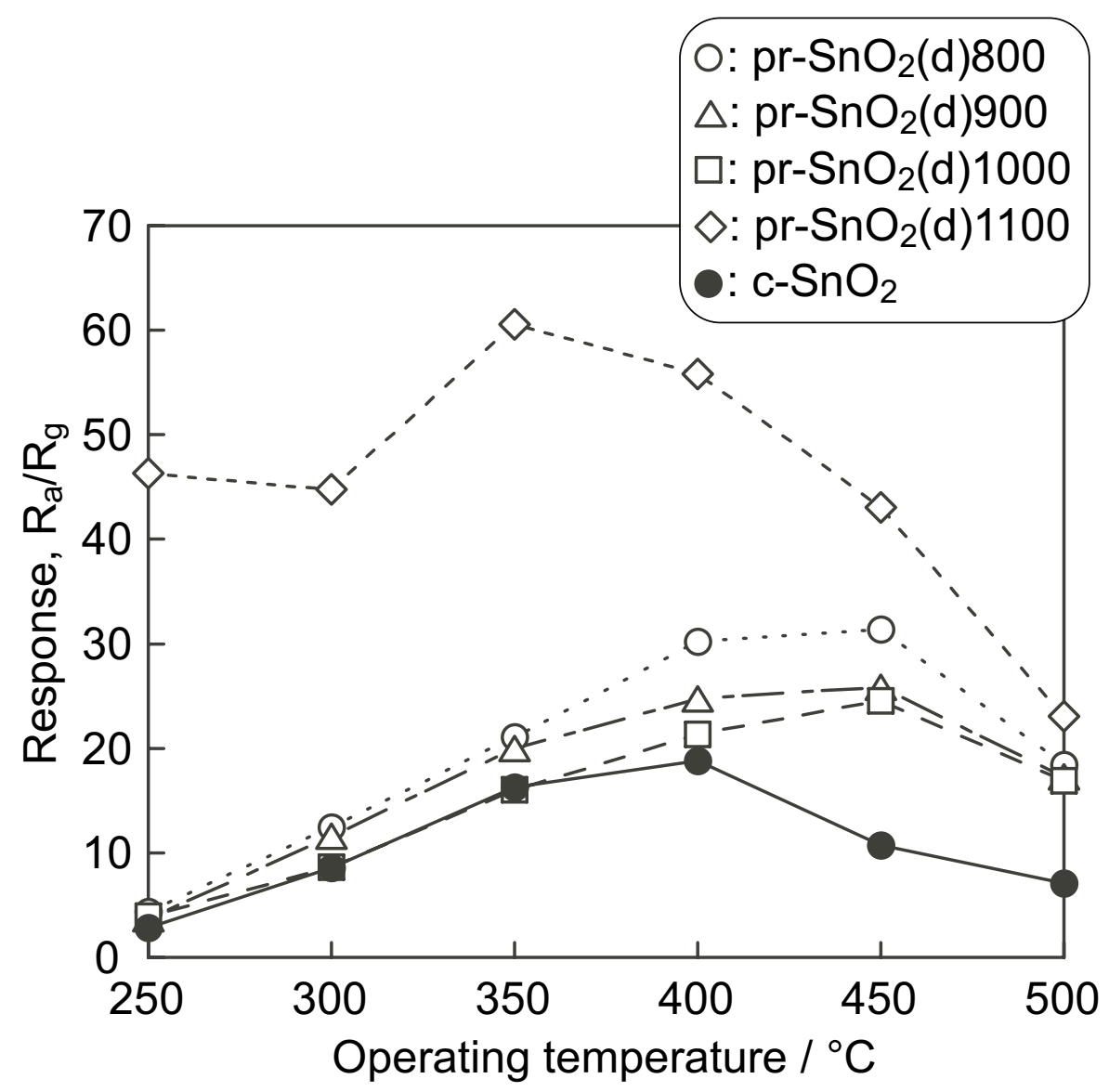

Fig. 7. Hieda et al. 


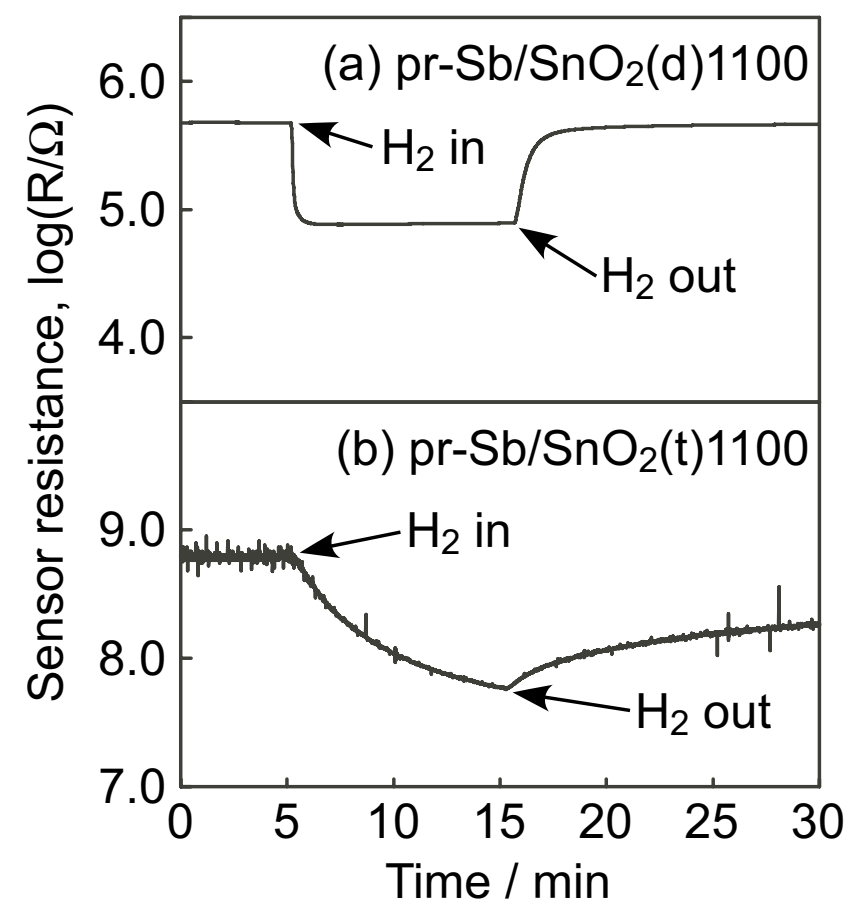

Fig. 8. Hieda et al.

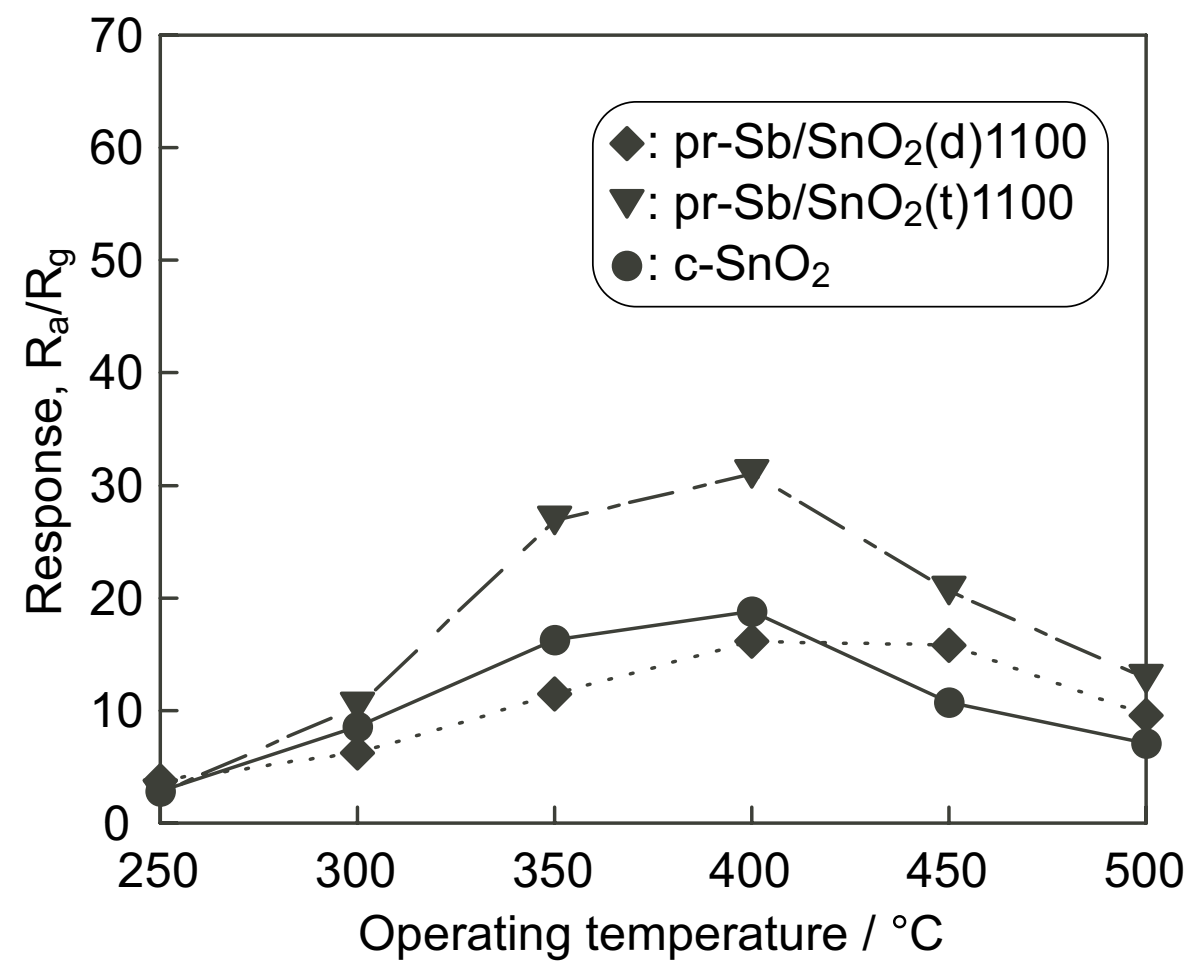

Fig. 9. Hieda et al. 